\title{
Observation Result Comment
}

National Cancer Institute

\section{Source}

National Cancer Institute. Observation Result Comment. NCI Thesaurus. Code C70956.

An optional additional description of the observation result provided in a free text format. 